\title{
Pengaruh Motif Batik Suminar Khas Kediri Dalam Meningkatkan Penjualan Suminar Batik Kediri
}

\author{
Ustadus Sholihin
}

Prodi Manajemen Fakultas Ekonomi Uniska

ustadus72sholihin@gmail.com

\begin{abstract}
Abstraksi
Batik merupakan ciri khas daerah atau wilayah bahkan bisa mencirikan suatu negara. Era sekarang ini bisnis batik mengalami perkembangan yang cukup siknifikan, dengan bukti menjamurnya UKM di berbagai wilayah di Indonesia. Dengan latar belakang secara umum tersebut peneliti berusaha mengambil topik tentang batik khas Kediri yang di produksi Oleh Joglo Suminar Batik Kediri. Joglo Suminar Batik Kediri mempunyai 5 motif batik khas kediri, diantaranya ada batik motif Flora, Motif fauna, motif seni budaya, motif wisata dan motif sosial. Kelima motif tersebut akan kami teliti sebagai variabel independent dan variabel dependentnya adalah omset penjualan.

Metode penelitian yang digunakan dalam peneltian ini uji multikolinearitas, Uji Autokorelasi, Uji Normalitas, Uji F ,Uji t dan Uji koefisien determinasi. Berdasarkan uji multikolinearitas dari 5 variabel yang di teliti, 2 mengandung multikolinearitas dan 3 variabel terbebas dari multikolinearitas. 2 Variabel tersebut adalah variable motif flora dan motif fauna. Tiga variable yang terbebas dari multikolinearitas adalah motif senibudaya, motif wisata, motif social. Hasil dari Uji Autokorelasi diperoleh nilai Durbin-Watson sebesar 0,450 berada pada posisi terjadi auto korelasi positif. Berdasarkan Uji Kelayakan Model, atau uji F model regresi yang diestimasikan layak. Hasil Uji koefisien determinasi, menghasilkan R Square yang sangat siknifikan sebesar 0,887. Hasil Interpretasi Model, diperoleh persamaan regresi y $=14,429 \quad+(-$ $0.011) \times 1+0,236 \times 2+0,021 \times 3+0,267 \times 4+(-0,212)$
\end{abstract}

Keyword Motif, penjualan.

\section{PENDAHULUAN}

Batik merupakan ciri khas daerah atau wilayah bahkan bisa mencirikan suatu negara.Era sekarang ini bisnis batik mengalami perkembangan yang cukup siknifikan, dengan bukti menjamurnya UKM di berbagai wilayah di Indonesia. Hal ini harus terus dikembangkan dan perhatikan oleh Pemerintah dengan pemodalan usaha mereka, karena setiap daerah /wilayah akan menggali potensi atau kekhasan atau ciri khas yang terdapat di daerah tersebut dan diangkat ke tingkat nasional atau bahkan tingkat internasional. Dengan cirihas tersebut akan menonjolkan kearifan lokal masing masing daerah / wilayah yang 
diangkat ke tingkat yang lebih luas lagi.

Dengan latar belakang secara umum tersebut peneliti berusaha mengambil topik tentang batik khas Kediri yang di produksi Oleh Joglo Suminar Batik Kediri. Joglo Suminar Batik Kediri mempunyai 5 motif batik khas kediri, diantaranya ada batik motif Flora, Motif fauna, motif seni budaya, motif wisata dan motif sosial. Kelima motif tersebut akan kami teliti sebagai variabel independent dan variabel dependentnya adalah omset penjualan. Dengan rumusan masalah sebagai berikut :

1. Bagaimana pengaruh batik motif Flora, motif Fauna, motif Seni Budaya dan motif Sosial secara simultan terhadap omzet penjualan di Joglo Batik Suminar Sekoto Kediri

2. Manakah diantara batik motif Flora, motif Fauna, motif Seni Budaya dan motif sosial yang mempunyai pengaruh dominan terhadap omzet penjualan di Joglo Batik Suminar Sekoto Kediri.

\section{LANDASAN TEORI}

\section{A. MOTIF BATIK SUMINAR KHAS KEDIRI}

Motif dan makna batik Suminar umumya berorientasi pada keadaan lingkungan sekitar di wilayah kabupaten/kota Kediri sehingga menghsilkan suatu batik yang disebut batik Bolleches dan mempunyai warna-warna yang terang dan tidak terikat oleh pakem-pakem batik, meliputi:

1) Flora / tumbuhan ; Daun Dewa, Daun Pisang, Brambang Sekoto, Anggrek, Mangga Podang, Pring Sedapur, Kembang Polkadot, Godong Gedang Ontong (daun dan bunga pisang), Teratai Ukel, Bambu Mini, Blarak Tanggung (daun kelapa Sedang), Anggrek Kangkung, Ron Telo (daun ketela), Petetan Beras kutah, Sulur seledri, Sekar Kantil (bunga kantil), Kangkung Seiket, Bunga Rambat, Garuda Teratai, daun Mangkok, Garuda Muka Suruhan, Teratai Mekar, Anggrek Truntum, Blarak Sempal (daun kelapa patah), Blarak Sempal Mini (daun kelapa patah mini), Vilokers, Ron Mawar Renteng (daun mawar berderet), Mawar melati, Semanggi Sulur, Sekar jagad Sekar renteng, Bunga Matahari, Daun Liar, Suruhan Ceplok, Anggrek Patrun, Villodendron, Kopi, Ron Kates, Pertiwi, Semanggi, Bunga Simpur Melati, Boketan, Seruni, Ron Kembar (daun kembar), Gemani, Bunga Dahlia, Podang Gunung, Buah Naga, Rosella, Anggur,

2) Fauna / hewan; Ikan Koi, Kupu Tapak Dara, Ulat Bulu, Suro lan Boyo, Ikan Cupang

3) Seni budaya; Kuda Lumping, Garuda Muka Kalpataru, Bangbangan Kediren, Pelem Garuda, Parangkeris Kuda Lumping, Kuda Lumping Kembar,

4) Wisata; Selomangkleng, Fenomena Kelud Erupsi, Anak Kelud, Kemilau SLG (Kemilau Simpang Lima Gumul), Barong, Parangsih SLG (Parangsih SLG Simpang Lima Gumul)

5) Sosial: RS Baptis kediri, keperawatan Pelem Garuda, Batik PSSI, Garuda Muka Mukti, Garuda Muka Liris, Garuda Muka Gemani, Garuda Muka Teratai Mekar, Garuda Muka Brantas, Garuda Muka Brantas, Garuda Muka Geragih, Genta, Garuda Muka Parangkeris, Sulur Awan, Sawunggaling.

Peran Pemerintah kabupaten/kota Kediri untuk menonjolkan batik Suminar sebagai ikon daerah sangat besar. Dibuktikan dengan melatih dan membina para pembatik, mengikutkan batik Suminar keberbagai macam acara baik lokal maupun internasional, 
mewajibkan para pegawai pemerintah daerah (pegawai kantor dan guru) dan anak-anak sekolah memakai pakaian batik pada hari rabu, kamis dan jumat.

https://jawatimuran.net.2016/10/13>batik

\section{B. Penjualan}

Menurut Sutamto (1997) tentang pengertian penjualan adalah : “ Usaha yang dilakukan manusia untuk menyampaikan barang dan jasa kebutuhan yang telah dihasilkannya kepada mereka yang membutuhkan dengan imbalan uang menurut harga yang telah ditentukan sebelumnya".

Sedang Winardi (1991) menyatakan penjualan adalah :

Proses dimana si penjual atau produsen memastikan mengaktifkan dan memuaskan kebutuhan atau keinginan pembeli/konsumen agar dicapai mufakat dan manfaat baik bagi si penjual maupun Si pembeli yang berkelanjutan dan menguntungkan kedua belah pihak. Dari pendapat tersebut maka penjualan itu merupakan kegiatan menawarkan /memasarkan barang dan jasa kepada pembeli yang berminat yang nantinya akan dibayar jika telah terjadi kesepakatan mengenai harga barang/jasa itu.

Beberapa cara untuk meningkatkan omzet penjualan toko anda, yaitu:

1). Mengutamakan kualitas dan inovasi produk

Tidak bisa dimungkiri lagi, kualitas produk adalah salah satu syarat utama untuk meningkatkan tingkat penjualannya.Dengan produk yang berkualitas, anda tidak perlu menunggu waktu lama untuk mendapatkan banyak custumer. Saat satu custumer puas dengan kualitas produk tersebut, dia tidak akan segan-segan mempromosikannya dengan orang lain. Daripada anda membuang uang untuk melakukan promosi, biarkanlah pelanggan anda yang melakukannya secara otomatis tanpa kita sadari Selama mereka diperlakukan dengan baik, mereka tidak akan sungkan untuk merekomendasikan bisnis anda ke keluarga atau kerabat.

Bisnis dengan produk yang sama di pasaran tidak akan tercapai maksimal jika anda hanya mengandalkan produk yang lama tanpa mengubah nilai dari produk tersebut. Inovasi sangat diperlukan bagi kelancaran usaha anda sekalipun anda memiliki modal yang cukup besar.Sebuah inovasi dalam bisnis itu mutlak diperlukan agar kita dapat bersaing didunia retail, namun tidak harus dilaksanakan atau dilakukan untuk mengubah produk lama secara keseluruhan. Inovasi merupakan suatu cara bagi anda untuk membuat suatu produk baru dengan metode baru atau dengan desain baru yang lebih baik dari produk lama yang telah atau belum pernah dipasarkan. inovasi juga bisa disebabkan karena permintaan pasar yang ingin mendapatkan barang baru dengan fungsi yang berbeda. Barang atau produk yang lama memang laku di pasaran namun konsumen menginginkan produk baru yang juga sama menariknya dengan produk lama. Kedua produk itu nantinya bisa memuaskan kebutuhan konsumen sehingga dapat meningkatkan omzet penjualan toko.

2). Memberi pelayanan baik kepada pelanggan

Dalam melakukan sebuah penjualan, hal pertama anda lakukan yaitu memberikan kesan baik kepada custumer anda. Semua custumer pada dasarnya adalah sama. Mereka samasama membeli produk anda karena didorong oleh suatu kebutuhan atau keinginan yang harus dipenuhi.Berapapun uang yang mereka keluarkan, berapapun produk yang mereka beli, mereka mempunyai hak untuk mendapatkan pelayanan terbaik. Jika mereka dikecewakan, mereka tidak akan sungkan-sungkan untuk menjelek-jelekkan toko anda dan bisnis anda di depan banyak orang. Beri layanan yang memuaskan dan custumer akan kembali kepada anda.

3). Melakukan promosi secara efektif dengan menjual lebih banyak kepada 
pelanggan

Beberapa trik efektif untuk membuat custumer melakukan pembelian produk kita dalam jumlah besar.Langkah sederhana ini adalah dengan membuat paket-paket produk.Paket produk ini bertujuan agar custumer membeli produk kita lebih dari satu produk, misalnya saja paket bundling, paket hemat, paket premium ataupun paket-paket saat periode tertentu (hari besar, hari istimewa, dan sebagainya).Sehingga omzet penjualan yang kita dapat lebih dari satu jenis produk dan custumer pun mendapatkan variasi produk.

4). Menambah outlet di berbagai daerah dengan tujuan target pasar baru

Dan mendapat pelanggan baru

Dalam meningkatkan dan mengembangkan usaha, diperlukan pemasaran yang lebih intensif.Salah satunya dalam usaha tersebut adalah dengan pembukaan outlet baru. Usaha membuka outlet baru sangat dibutuhkan karena kejenuhan pada satu area pemasaran membutuhkan pembukaan area pemasaran baru agar perkembangan dan kemajuan target omzet penjualan dapat dicapai sehingga memungkinan custumer dapat membeli produk anda, yang lokasinya dekat dengan tempat tinggalnya. Tujuan utama dalam menambah outlet yaitu meningkatkan layanan kepada custumer serta menjadikan salah satu caras bisnis dalam rangka meningkatkan jumlah custumer baru di berbagai daerah. Anda harus melihat apakah suatu segmen potensial memiliki karakteristik yang secara umum dalam menarik seperti ukuran, pertumbuhan, profitabilitas, skala ekonomi, resiko yang rendah dan lain-lain. anda harus memastikan bahwa outlet barunya memiliki segmen pasar yang dibidik itu cukup besar dan akan cukup menguntungkan bagi anda. Setelah anda mengidentifikasi peluang target pasar, selanjutnya adalah mengevaluasi beragam segmen tersebut untuk memutuskan segmen mana yang menjadi target pasar. anda juga perlu mempertimbangkan apakah berinvestasi disuatu daerah dilokasi dapat memberikan keuntungan dan menghindari kerugian.

5). Mengadakan diskon produk dan penawaran khusus

Konsumen akan sangat senang jika mendapatkan diskon saat membeli produk. Untuk menawarkan diskon, ada beberapa hal yang perlu anda perhatikan.Berikanlah diskon rasional yang tidak memberatkan anda sesuai harga pokok produksi anda. Jika memberikan diskon terlalu besar, itu akan menjadi bumerang sendiri bagi anda. Jangan terlalu sering memberikan diskon karena diskon seharusnya diberikan pada saat tertentu, efektifitasnya biasanya menjelang hari raya dan akhir tahun juga dalam pemberian discon gunakan jangka waktu terbatas. Penawaran khusus terkadang lebih menarik daripada diskon, sehingga custumer dapat melihat bahwa penawaran khusus biasanya diberikan demi meningkatkan loyalitas pembelian custumer, walaupun dalam garis besar penawaran khusus diberikan agar custumer lebih cepat membayar.

http://ekonomi.kompasiana.com/wirausaha/2013/11/06/cara-jitu-meningkatkan-omzet605655.html

\section{MODEL / KERANGKA TEORITIK}

Berdasarkan landasan teori diatas dan rumusan masalah maka peneliti dapat menentukan model / Kerangka Teoritik yang di gunakan sebagai berikut : 
Gambar 1.

Model / Kerangka Teoritik

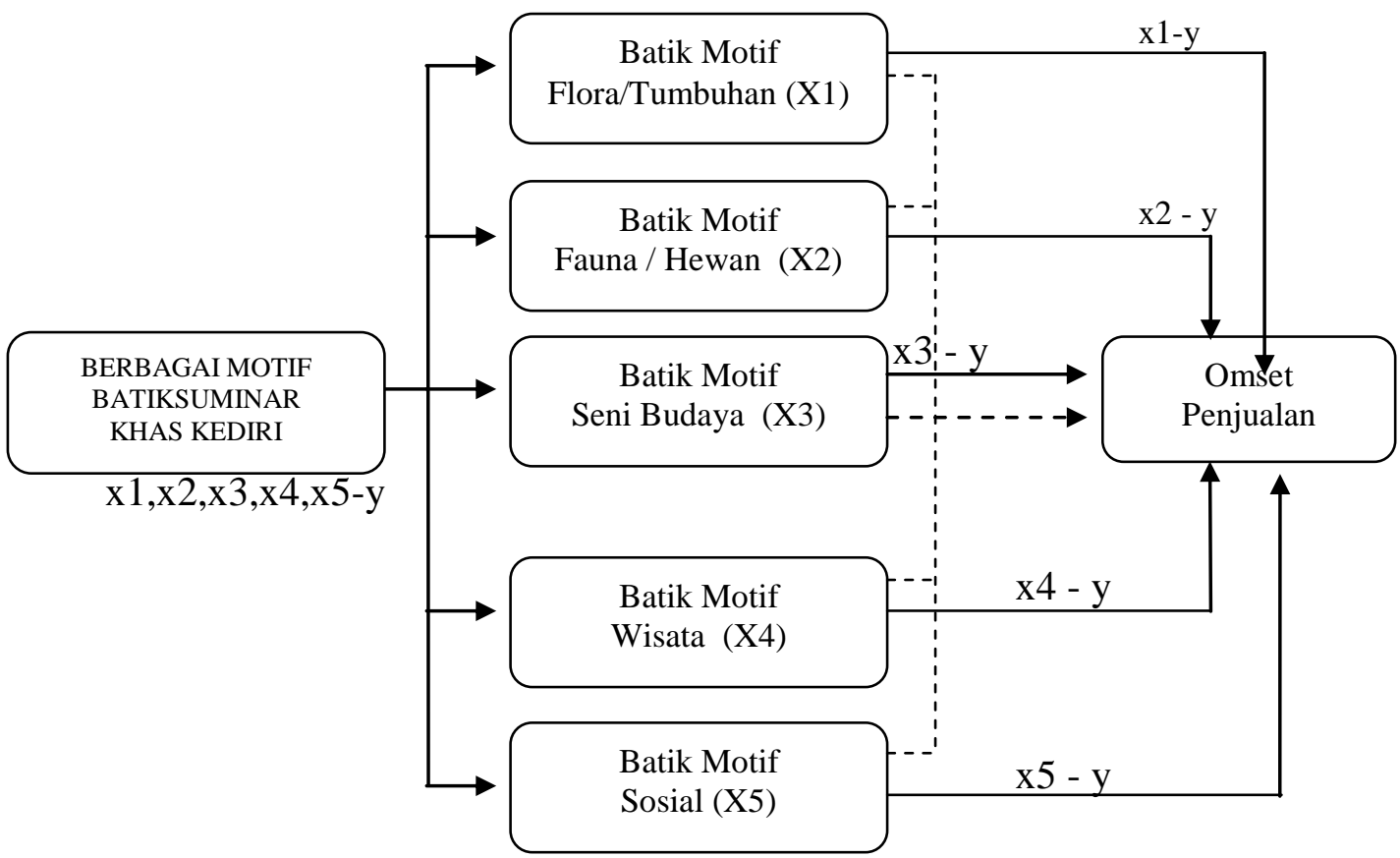

\section{HIPOTESIS PENELITIAN}

Berdasarkan landasan teori diatas dan model kerangaka teoritik yang dibuat, maka peneliti menentukan hipotesis penelitian sebagai berikut :

1. Diduga batik motif Flora, motif Fauna, motif Seni Budaya dan motif Sosial secara simultan berpengaruh siknifikan terhadap omzet penjualan di Joglo Batik Suminar Sekoto Kediri

2. Diduga batik motif Flora mempunyai pengaruh paling dominan dibanding dengan batik motif Fauna, batik motif Seni Budaya, batik motif wisata dan batik motif sosial terhadap omzet penjualan di Joglo Batik Suminar Sekoto Kediri

\section{METODE PENELITIAN}

Metode penelitian yang digunakan oleh peneliti adalah sebagai berikut :

\section{Lokasi Penelitian}

Lokasi tempat penelitian adalah Joglo Suminar Batik Kediri, yang beralamatkan di Jalan KH. Dewantara No 74, Tulungrejo, Badas - Pare - Kediri - JawaTimur - 64212 - Indoesia.

\section{Populasi Dan Sampel}

Dalam bagian ini peneliti menjelaskan populasi dan sampel yang digunakan. Adapun yag dimaksud dengan populasi adalah sebagai berikut: 
Menurut Sugiyono, (2011) mendefinisikan populasi sebagai berikut : "Populasi adalah wilayah generalisasi yang terdiri atas : obyek/subyek yang mempunyai kualitas dan karakteristik tertentu yang ditetapkan oleh peneliti untuk dipelajari dan kemudian ditarik kesimpulannya". Adapun menurut Sedamaryanti,(2002), populasi adalah : "Populasi adalah himpunan keseluruhan karakteristik dari obyek yang diteliti".

Adapun yang dimaksud dengan sampel menurut Sugiyono, (2011) :

Sampel adalah bagian dari jumlah dan karakteristik yang dimiliki oleh populasi. Bila populasi besar, dan peneliti tidak mungkin mempelajari semua yang ada pada populasi, misalnya karena keterbatasan dana, tenaga dan waktu, maka peneliti dapat menggunakan sampel yang diambil dari populasi itu. Apa yang dipelajari dari sampel, kesimpulannya akan dapat diberlakukan untuk populasi. Untuk itu sampel yang diambil dari populasi harus betul betul representatif (mewakili).

Sedangkan sampel menurut Sedamaryanti,(2002) adalah sebagai berikut : “ sampel adalah kelompok kecil yang diamati dan merupakan bagian dari populasi sehingga sifat dan karakteristik populasi juga dimiliki oleh sampel". Sedangkan menurut Ferguson ( 1976 ) , dalam Sedamaryanti,(2002) mendefinisikan sampel adalah : “ beberapa bagian kecil atau cuplikan yang ditarik dari populasi”.

Berdasarkan definisi diatas maka populasi dalam penelitian ini adalah pelanggan Joglo Suminar Batik Kediri.Adapun yang menjadi populasinya adalah sebagian dari pelanggan Joglo Suminar Batik Kediri.

\section{Teknik Sampling}

Teknik sampling merupakan teknik mengambil sampel dari populasinya, adapun teknik sampling yang peneliti gunakan adalah teknik sampling insidental. Adapun yang dimaksud dengan teknik sampling insidental menurut Sugiyono, (2011) adalah sebagai berikut :

Sampling insidental adalah teknik penentuan sampel berdasarkan kebetulan, yaitu siapa saja yang secara kebetulan/insidental bertemu dengan peneliti dapat digunakan sebagai sampel, bila dipandang orang yang kebetulan ditemui itu cocok sebagai sumber data.

Cara kami melakukan teknik sampling dengan menggunakan teknik insidental adalah peneliti selama kurang lebih 2 minggu berada di Joglo Suminar Batik Kediri. Pada waktu ada pelanggan yang membeli batik Suminar kita minta waktu untuk mengisi angket.

\section{Penentuan Jumlah Sampel}

Penentuan jumlah sampel dalam penelitian ini menggunakan dasar tabel penentuan jumlah sampel dari populasi tertentu yang dikembangkan dari Isaac dan Michael, untuk tingkat kesalahan, 1\%, 5\% dan 10\%.Adapun tabel yang digunakan untuk menentukan besarnya sampel peneliti taruh dilampiran.Besarnya populasi dalam penelitiaan ini adalah 500 pelanggan, berdasarkan tabel dari Isaac dan Michael dengan tingkat kesalahan $10 \%$ maka besarnya sampel adalah 176 pelanggan batik Suminar.

\section{Data Dan Teknik Pengumpulannya}

Pengumpulan data yang peneliti gunakan adalah sebagai berikut :

a. Pengamatan ( Observasi )

Pengamatan atau observasi adalah cara pengumpulan data dengan terjun dan meliht langsung kel lapangan ( laboratorium) terhadap objek yang diteliti ( populasi atau sampel )

b. Penelusuran Literatur 
Penelusuran Literatur adalah cara pengumpulan data dengan menggunakan sebagian atau seluruh data yang telah ada atau laporan data dari peneliti sebelumnya. Penelusuran literatur disebut juga pengamatan tidak langsung.

c. Penggunaan Kuesioner

Penggunaan kuesioner adalah cara pengumpulan data dengan menggunakan dafatar pertanyaan ( angket ) atau daftar isian terhadap obyek yang diteliti ( populasi atau sampel )

d. Wawancara ( Interviu )

Wawancara adalah cara pengumpulan data dengan mengadakan tanya jawab langsung kepada obyek yang diteliti atau kepada perantara yang mengetahui persoalan dari obyek yang diteliti.

Igbal Hasan, ( 2004)

\section{Identifikasi Variabel}

Identifikasi dlam penelitian ini adalah sebagai berikut :

1. Variabel Independent yang meliputi :
a. Variabel x1 : Batik Motif Flora / Tumbuhan
b. Variabel x2 : Batik Motif Fauna / Hewan
c. Variabel x3 : Batik Motif Seni Budaya
d. Variabel x4 : Batik Motif Wisata
e. Variabel x5 : Batik Motif Sosial

2. Variabel Dependent yang meliputi :

a. Variabel y: Omset Penjualan

\section{Definisi Operasional Variabel}

Definisi Operasional Variabel dalam penelitian ini, menjelaskan tentang definisi operasional yang terdapat di Joglo Suminar Batik, sebagai berikut

1. Variabel Independent yang meliputi :

a. Variabel x 1 : Batik Motif Flora / Tumbuhan, menjelaskan tentang jenis jenis batik motif tumbuhan yang digunakan di Joglo Suminar Batik, adapun indikator yang digunakan dalam penelitian ini adalah jenis jenis tumbuhan sebagai berikut :
1). Batik Motif Bunga
2). Batik Motif Daun
3). Batik Motif Buah
4). Batik Motif Pohon

b. Variabel x2 : Batik Motif Fauna / Hewan menjelaskan tentang jenis jenis batik motif hewan yang digunakan di Joglo Suminar Batik, adapun indikator yang digunakan dalam penelitian ini adalah jenis jenis hewan, sebagai berikut:

1). Batik Motif Ikan Koi

2). Batik Motif Kupu Kupu

3). Batik Motif Tapak Dara

4). Batik Motif Ulat Bulu

5). Batik Moti Bangau

6). Batik Motif Ikan Cupang

c. Variabel x3 : Batik Motif Seni Budaya, Batik Motif Seni Budaya menjelaskan tentang jenis jenis batik motif Seni Budaya yang digunakan di Joglo Suminar Batik, adapun indikator yang digunakan dalam penelitian ini adalah jenis jenis seni budaya sebagai berikut :

1). Batik Motif Kuda Lumping

2). Batik Motif Garuda Muka Kalpataru

3). Batik Motif Bangbangan Kediren 
4). Batik Motif Pelem Garuda

5). Batik Moti Kuda Lumping Kembar

6). Batik Motif Ikan Parangkeris Kuda Lumping

d. Variabel x4 : Batik Motif Wisata, Batik Motif Wisata menjelaskan tentang jenis jenis batik motif Wisata yang digunakan di Joglo Suminar Batik, adapun indikator yang digunakan dalam penelitian ini adalah jenis jenis tempat wisata yng ada di Kediri, sebagai berikut :

1). Batik Motif Selomangkleng

2). Batik Motif Fenomena Kelud Erupsi

3). Batik Motif Anak Kelud

4). Batik Motif Kemilau SLG - Simpang Lima Gumul

5). Batik Motif Parangsih SLG - Simpang Lima Gumul

e. Variabel x5 : Batik Motif Sosial, Batik Motif Sosial menjelaskan tentang jenis jenis batik motif Sosial yang digunakan di Joglo Suminar Batik, adapun indikator yang digunakan dalam penelitian ini adalah jenis jenis instansi / lembaga yang memesan batik Suminar sebagai berikut :

1). Batik Motif RS Baptis Kediri

2). Batik Motif Uniska Kediri

3). Batik Motif BNN Kota Kediri

4). Batik Motif Genta Pare

5). Batik Motif Garuda Muka Brantas

2. Variabel Dependent yang meliputi :

a. Variabel y : Volume Penjualan, merupakan besarnya kegiatan kegiatan yang dilakukan secara efektif oleh penjualan untuk mendorong agar konsumen melkukan pembelian dengan indikator sebagai berikut :

1). Harga Kain Batik

2). Promosi Batik

3). Kualitas Batik

4). Saluran Distribusi Batik

5). Produk Batik

8. Teknik Analisis

Teknik Analisis yang digunakan dalam penelitian ini adalah sebagai berikut :
a). Uji Validitas
b). Uji Reliabilitas
c). Uji Regresi Linear
d) Uji F
e). Uji t

\section{HASIL DAN PEMBAHASAN}

\section{Multikolinearitas}

Dari hasil analysis asumsi klasik, yang peneliti lakukan menghasilkan out put uji multikolinearitas sebagai berikut : 
Tabel 4.1

Output Multikolinearitas

( Coefficients )

\begin{tabular}{|c|c|c|c|c|c|c|c|c|}
\hline \multicolumn{9}{|c|}{ Coefficients $^{\mathrm{a}}$} \\
\hline & \multirow{2}{*}{ Model } & \multicolumn{2}{|c|}{$\begin{array}{l}\text { Unstandardized } \\
\text { Coefficients }\end{array}$} & \multirow{2}{*}{$\begin{array}{c}\text { Standardized } \\
\text { Coefficients } \\
\text { Beta }\end{array}$} & \multirow[t]{2}{*}{$\mathrm{t}$} & \multirow{2}{*}{ Sig. } & \multicolumn{2}{|c|}{$\begin{array}{c}\text { Collinearity } \\
\text { Statistics }\end{array}$} \\
\hline & & B & Std. Error & & & & Tolerance & VIF \\
\hline \multirow[t]{6}{*}{1} & (Constant) & 14.429 & .817 & & 17.654 & .000 & & \\
\hline & Motifflora & -.011 & .027 & -.036 & -.391 & .696 & .078 & 12.885 \\
\hline & Motiffauna & .236 & .027 & .761 & 8.698 & .000 & .087 & 11.531 \\
\hline & Motifsenibudaya & .021 & .038 & .034 & .540 & .590 & .169 & 5.918 \\
\hline & Motifwisata & .267 & .031 & .635 & 8.659 & .000 & .123 & 8.102 \\
\hline & Motifsosial & -.212 & .032 & -.469 & -6.603 & .000 & .132 & 7.603 \\
\hline
\end{tabular}

Nilai VIF untuk variable Motif Flora, Motif Fauna, Motif Seni Budaya, Motif Wisata Dan Motif Sosial mempunyai nilai yang berbeda beda. Dalam penelitian ini penulis menentukan ukuran VIF sebesar 10 bukan 5 . Dari hasil analisis yang mendapatkan nilai diatas 10 yaitu motif flora dan motif fauna kedua variable tersebut terjadi multikolinearitas. Sedangkan motif yang lain yaitu motif seni budaya, motif wisata dan motif social tidak terjadi multikolinearitas karena nilai VIF dibawah 10.

Berdasarkan Syarat uji asumsi klasik jika regresi liner dengan OLS, maka model regresi linear yang baik yaitu suatu model yang tidak mengandung atau terbebas dari adanya multikolinearitas.

Dengan demikian model regresi linear diatas dari 5 variabel yang diteliti, 2 variabel mengandung multikolinearitas dan 3 variabel terbebas atau tidak mengandung multikolinearitas.

\section{Autokorelasi}

Tabel 4.2

Output Autokorelasi

( Model Summary )

\begin{tabular}{|c|c|c|c|c|c|c|c|c|c|c|}
\hline \multicolumn{11}{|c|}{ Model Summary ${ }^{\mathbf{b}}$} \\
\hline \multirow[b]{2}{*}{ Model } & \multirow[b]{2}{*}{$\mathrm{R}$} & \multirow[b]{2}{*}{$\begin{array}{c}\mathrm{R} \\
\text { Square }\end{array}$} & \multirow[b]{2}{*}{$\begin{array}{c}\text { Adjusted R } \\
\text { Square }\end{array}$} & \multirow[b]{2}{*}{$\begin{array}{l}\text { Std. Error of the } \\
\text { Estimate }\end{array}$} & \multicolumn{5}{|c|}{ Change Statistics } & \multirow[b]{2}{*}{$\begin{array}{l}\text { Durbin- } \\
\text { Watson }\end{array}$} \\
\hline & & & & & $\begin{array}{l}\text { R Square } \\
\text { Change }\end{array}$ & F Change & df1 & df2 & \begin{tabular}{|c|} 
Sig. F \\
Change
\end{tabular} & \\
\hline 1 & $.942^{\mathrm{a}}$ & .887 & .884 & .20268 & .887 & 267.169 & 5 & 170 & .000 & .450 \\
\hline \multicolumn{11}{|c|}{ a. Predictors: (Constant), Motifsosial, Motifsenibudaya, Motifwisata, Motiffauna, Motifflora } \\
\hline \multicolumn{11}{|c|}{ b. Dependent Variable: Omsetpenjualan } \\
\hline
\end{tabular}

Dari hasil output uji autokorelasi, diperoleh nilai autokorelasi positif berdasarkan nilai Durbin Watson sebesar 0,450. Dengan data $\mathrm{k}=6$, yaitu 5 variabel independen dan 1 variabel dependent, besarnya $\mathrm{n}=176$ responden. Berdasarkan table Durbin Watson nilai dl $($ Durbin Lower ) $=1,613$ dan nilai DU ( Durbin Upper ) sebesar $=1,735$. Maka langkah selanjutnya $4-\mathrm{dl}=4-1,613=2,387$ dan $4-\mathrm{du}=4-1,735=2,265$. Nilai 4 , merupakan nilai dasar yang di gunakan untuk menghitung dl dan du. 


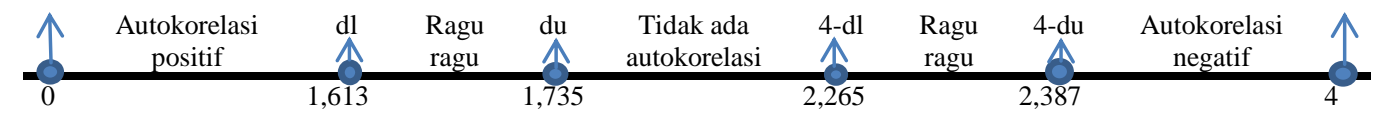

Jadi berdasarkan table Durbin Watson nilai sebesar 0,450 berada pada posisi Autokorelasi positif.

\section{Heterokedastisitas}

Dari hasil analysis asumsi klasik, yang peneliti lakukan menghasilkan out put uji Heterokedastisitas sebagai berikut :

Gambar 4.1

Output Uji Heterokedastisitas

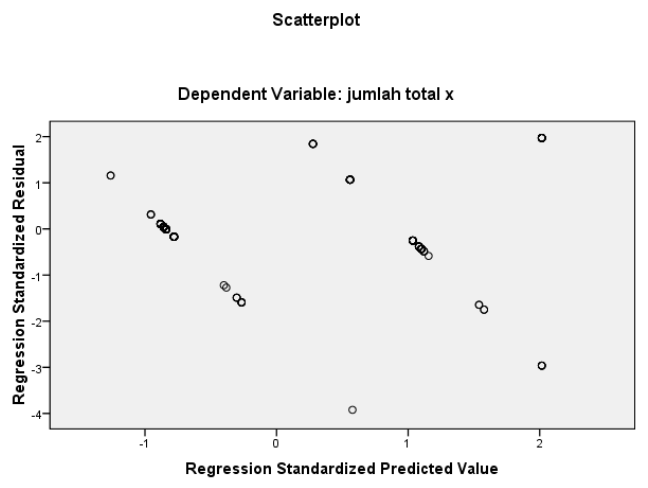

Pengujian heterokedastisitas dengan hasil seperti membuat alur sebaran (Scatterplot) antara residual standarisasi dengan nilai prediksi standarisasi dari variable terikat yang telah distandarisasi. Dari gambar diatas sebaran titik membentuk pola yaitu 2 garis dari pojok kiri atas ke kanan bawah dan satu sebaran di pojok kanan atas.

Jadi berdasarkan output hasil analysis data yang peneliti lakukan mengandung heterokedastisitas karena membentuk suatu pola. Berdasarkan uji asumsi klasik data yang baik jika tidak mengandung heterokedastisitas dengan ciri gambar sebaran titik titiknya tidak membentuk pola atau disebut homoskedastisitas.

Uji heterokedastisitas atau scatterplot sangat rentan terhadap kesalahan dalam penarikan kesimpulannya, karena sifatnya yang sangat subyektif dari peneliti.Hai ini di sebabkan ada tidaknya bentuk atau pola yang menentukan seorang peneliti. Jadi bisa dikatakan menurut sebagian orang gambar tersebut membentuk pola tapi menurut sebagian yang lain tidak membentuk pola. Karena tidak ada ukuran yang pasti dimana gambar scatterplot membentuk pola dan gambar scatterplot tidak membentuk pola.Jadi keputusan dalam penelitian ini hanya mengandalkan pengamatan peneliti.

\section{Normalitas}

Dari hasil analysis asumsi klasik, yang peneliti lakukan menghasilkan out put uji Normalitas sebagai berikut : 


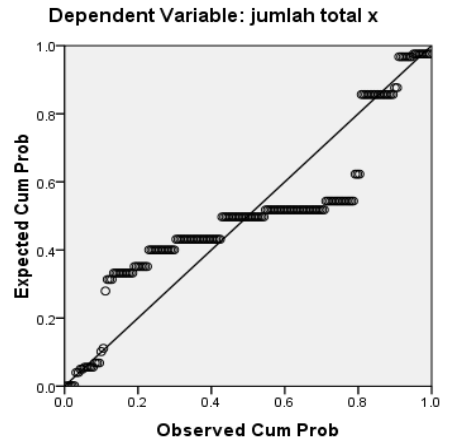

Uji Normalitas dari hasil output gambar diatas, menurut peneliti residual yang dibentuk model regresi linear terdistribusi normal dengan pendekatan Normal P-P plot dapat dilihat sebaran titik titik yang terdapat pada gambar diatas. Jika sebaran titik titik mendekati atau rapat di garis lurus diagonal maka dapat dikatakan bahwa data yang dianalisis residual terdistribusi normal, tapi jika sebaran titik titik semakin menjauhi garis lurus diagonal dapat dikatakan tidak terdistribusi normal.

Kelemahan dari uji Normalitas yaitu sifatnya yang sangat subyektif, artinya jika peneliti berpendapat sebaran titik titik mendekati garis lurus diagonal maka dikatakan mengandung Normalitas dan sebaliknya jika peneliti berpendapat sebaran titik titik menjauhi garis lurus diagonal maka dikatakan tidak mengandung Normalitas.Karena tidak ada batasan yang jelas mengenai jauh dekatnya sebaran titik titik tersebut sangat dimungkinkan terjadinya kesalahan dalam penarikan kesimpulan.

\section{Uji Kelayakan Model}

\section{Uji Keterandalan Model ( Uji F )}

Hasil dari proses analysis regresi berganda diperoleh output, yang menjelaskan tentang uji $\mathrm{F}$ atau uji keterandalan suatu model adalah sebagai berikut :

Tabel 4.3

Output Analysis Regression

( Uji F )

\begin{tabular}{|c|c|c|c|c|c|c|}
\hline \multicolumn{7}{|c|}{ ANOVA $^{\text {b }}$} \\
\hline \multicolumn{2}{|c|}{ Model } & Sum of Squares & $\mathrm{df}$ & Mean Square & $\mathrm{F}$ & Sig. \\
\hline \multirow[t]{3}{*}{1} & Regression & 54.875 & 5 & 10.975 & 267.169 & $.000^{\mathrm{a}}$ \\
\hline & Residual & 6.983 & 170 & .041 & & \\
\hline & Total & 61.858 & 175 & & & \\
\hline \multicolumn{7}{|c|}{$\begin{array}{l}\text { a. Predictors: (Constant), item } x \text { ke } 5 \text {, item } x \text { ke } 3 \text {, item } x \text { ke } 4 \text {, item } x \text { ke } 2 \text {, item } x \text { ke } \\
1\end{array}$} \\
\hline
\end{tabular}

Uji F sering disebut sebagai Uji Secara Simultan Model, yaitu uji secara bersama sama antara variable x yang berjumlah 5 variabel terhadap 1 variabel y. Ada juga yang menyebutnya sebagai Uji Keterandalan Model atau Uji Keterlayakan Model atau yang paling popular disebut sebagai Uji F.

Uji $\mathrm{F}$ digunakan untuk mengidentifikasi apakah suatu model regresi yang diprediksi layak ( feasible ) atau tidak layak ( Unfeasible ). Layak mempunyai arti yaitu 
Andal maksudnya persamaan yg diperoleh hasil dari analysis mampu menjelaskan pengaruh antara 5 variabel bebas terhadap 1 variabel terikat.

Dalam penelitian ini, antara variable Motif Flora, Motif Fauna, Motif Seni Budaya, Motif Wisata Dan Motif Sosial secara bersama sama ( Simultan ) mempunyai pengaruh terhadap Omzet penjualan Di Rumah Joglo Suminar Batik Sekoto Kediri. Besarnya nilai Uji $\mathrm{F}$ hitung dalam penelitian ini ditunjukkan pada angka 267.169 sedangkan angka siknifikansinya sebesar 0,000. Dalam penelitian ini nilai Probabilitas F hitung di tentukan sebesar 0,05 atau sederajat dengan $5 \%$. Jika nilai siknifikansinya dibawah 0,05 maka dapat dikatakan model regresi yang diestimasi Layak dan jika yang terjadi sebaliknya adalah jika nilai siknifikansinya lebih besar dari 0,05 maka model regresi yang diestimasi tidak layak. Kesimpulannya hasil uji berdasar uji F model regresi yang diestimasi dalam penelitian ini adalah layak

\section{Uji Koefisien Regresi ( Uji t )}

Tabel 4.4

Output Analysis Regression

( Uji t )

\begin{tabular}{|c|c|c|c|c|c|c|c|c|}
\hline \multicolumn{9}{|c|}{ Coefficients $^{\mathrm{a}}$} \\
\hline & \multirow{2}{*}{ Model } & \multicolumn{2}{|c|}{$\begin{array}{l}\text { Unstandardized } \\
\text { Coefficients }\end{array}$} & \multirow{2}{*}{$\begin{array}{c}\text { Standardized } \\
\text { Coefficients } \\
\text { Beta }\end{array}$} & \multirow[t]{2}{*}{$\mathrm{t}$} & \multirow{2}{*}{ Sig. } & \multicolumn{2}{|c|}{$\begin{array}{c}\text { Collinearity } \\
\text { Statistics }\end{array}$} \\
\hline & & B & Std. Error & & & & Tolerance & VIF \\
\hline \multirow[t]{6}{*}{1} & (Constant) & 14.429 & .817 & & 17.654 & .000 & & \\
\hline & Motifflora & -.011 & .027 & -.036 & -.391 & .696 & .078 & 12.885 \\
\hline & Motiffauna & .236 & .027 & .761 & 8.698 & .000 & .087 & 11.531 \\
\hline & Motifsenibudaya & .021 & .038 & .034 & .540 & .590 & .169 & 5.918 \\
\hline & Motifwisata & .267 & .031 & 635 & 8.659 & .000 & .123 & 8.102 \\
\hline & Motifsosial & -.212 & .032 & -.469 & -6.603 & .000 & .132 & 7.603 \\
\hline
\end{tabular}

Uji t atau Uji Koefisien Regresi disebut juga uji parsial antara variable x terhadap variable y .Uji Parsial yaitu uji secara terpisah atau sendiri sendiri dimana x1 dengan y, $\mathrm{x} 2$ dengan y dan seterusnya.Dalam penelitian ini variable $\mathrm{x}$ motif flora diuji dengan omzet penjulan, kemudian motif fauna diuji dengan omzet penjualan, motif senibudaya di uji dengan omzet penjualan, motif wisata dengan omzet penjualan dan yang terakhir motif social diuji dengan omzet penjualan.

Dalam uji t ini dimaksudkan untuk menguji parameter yaitu koefisien regresi yang di duga mampu untuk meramalkan persamaan model regresi linear berganda sudah mampu menjadi parameter yang tepat atau belum.Maksudnya apakah perilaku beberapa motif diatas dalam penelitian ini sudah mampu menjelaskan perilakunya dalam mempengaruhi omzet penjualan.

Jika nilai probabilitas uji t hitung siknifikansinya lebih kecil dari 0,05 atau 5\% maka dapat dikatakan variable bebas 5 motif diatas berpengaruh siknifikan terhadap omzet penjualan, dan sebaliknya jika nilai probabilitasnya diatas 0,05 atau $5 \%$ maka dikatakan 5 motif variable bebas diatas tidak berpengaruh secara siknifikan pada taraf keyakinan $95 \%$.

variable variable Motif Flora, Motif Fauna, Motif Seni Budaya, Motif Wisata Dan Motif Sosial secara bersama sama ( Simultan ) mempunyai pengaruh terhadap Omzet penjualan Di Rumah Joglo Suminar Batik Sekoto Kediri, Motif Fauna, Motif Seni Budaya , Motif Wisata dan Motif Sosial secara bersama sama (Simultan) mempunyai pengaruh terhadap Omzet penjualan Di Rumah Joglo Suminar Batik Sekoto Kediri 
Dapat dikatakan dalam penelitian ini variable bebas Motif Flora berpengaruh tidak siknifikan terhadapOmzet penjualan Di Rumah Joglo Suminar Batik Sekoto Kediri karena nilainya siknifikansinya sebesar 0,696 atau $69 \%$, Motif Fauna berpengaruh siknifikan terhadap Omzet penjualan Di Rumah Joglo Suminar Batik Sekoto Kediri nilai siknifikansinya sebesar 0,000 atau 0\%, Motif Seni Budaya berpengaruh tidak siknifikan terhadap omzet penjualan karena nilai siknifikansinya sebesar 0,590 atau 59\%, Motif Wisata berpengaruh siknifikan terhadap omzet penjualan karena nilai siknifikansinya sebesar 0,000 atau 0\% Dan Motif Sosial berpengaruh secara siknifikan terhadap omzet penjualan karena nilai siknifikansinya sebesar 0,000 atau 0\% dengan taraf keyakinan 95\%

\section{Koefisien Determinasi}

Hasil dari proses analysis regresi berganda diperoleh output koefisien determinant sebagai berikut :

Tabel 4.5

Output Analysis Regression ( R Square )

\begin{tabular}{|l|r|r|r|r|r|}
\hline \multicolumn{7}{|c|}{ Model Summary $^{\mathbf{b}}$} \\
\hline Model & $\mathrm{R}$ & R Square & $\begin{array}{c}\text { Adjusted R } \\
\text { Square }\end{array}$ & $\begin{array}{c}\text { Std. Error of the } \\
\text { Estimate }\end{array}$ & $\begin{array}{c}\text { Durbin- } \\
\text { Watson }\end{array}$ \\
\hline 1 & $.942^{\mathrm{a}}$ & $\mathbf{. 8 8 7}$ & .884 & .20268 & .450 \\
\hline \multicolumn{7}{|l}{ a. Predictors: (Constant), item x ke 5, item x ke 3, item x ke 4, item x ke 2, item x ke 1 } \\
\hline
\end{tabular}

Besarnya nilai koefisien determinasi menjelaskan pengaruh variable bebas yaitu 5 motif batik terhadap omzet penjualan .Bisa juga dikatakan proporsi pengaruh seluruh variable bebas terhadap variable terikat. Dalam penelitian ini nilai koefisien determinasi dapat diukur dengan nilai $\mathrm{R}$ Square. Jika dilihat besarnya nilai $\mathrm{R}$ Square dari data diatas menunjukkan angka sebesar 0,887 atau $88,7 \%$. Artinya variable bebas yang terdiri dari Motif Flora, Motif Fauna, Motif Seni Budaya , Motif Wisata Dan Motif Sosial mampu mempengaruhi variable terikat yaitu Omzet penjualan Di Rumah Joglo Suminar Batik Sekoto Kediri sebesar $88,7 \%$ sedangkan sisanya $11,3 \%$ atau $(100-88,7=11,3)$ dipengaruhi variable lain yang tidak ada dalam model atau $11,3 \%$ dipengaruhi variable di luar yang diteliti. Jadi kesimpulannya 88,7 \% variable x , 5 motif mampu mempengaruhi terhadap variable y omzet penjualan.

\section{Interpretasi Model}

Hasil dari proses analysis regresi berganda diperoleh output sebagai berikut :

Tabel 4.5

Output Analysis Regression

(Unstandardized Coefficients)

\begin{tabular}{|c|c|c|c|c|c|c|c|c|}
\hline \multicolumn{9}{|c|}{ Coefficients $^{\mathrm{a}}$} \\
\hline & \multirow[t]{2}{*}{ Model } & \multicolumn{2}{|c|}{$\begin{array}{l}\text { Unstandardized } \\
\text { Coefficients }\end{array}$} & \multirow{2}{*}{$\begin{array}{c}\text { Standardized } \\
\text { Coefficients }\end{array}$} & \multirow{2}{*}{$\mathrm{t}$} & \multirow{2}{*}{ Sig. } & \multicolumn{2}{|c|}{ Collinearity Statistics } \\
\hline & & B & Std. Error & & & & Tolerance & VIF \\
\hline \multirow[t]{6}{*}{1} & (Constant) & 14.429 & .817 & & 17.654 & .000 & & \\
\hline & item $\mathrm{x}$ ke 1 & -.011 & .027 & -.036 & -.391 & .696 & .078 & 12.885 \\
\hline & item $\mathrm{x}$ ke 2 & .236 & .027 & .761 & 8.698 & .000 & .087 & 11.531 \\
\hline & item $\mathrm{x}$ ke 3 & .021 & .038 & .034 & .540 & .590 & .169 & 5.918 \\
\hline & item $\mathrm{x}$ ke 4 & .267 & .031 & .635 & 8.659 & .000 & .123 & 8.102 \\
\hline & item $\mathrm{x}$ ke 5 & -.212 & .032 & -.469 & -6.603 & .000 & .132 & 7.603 \\
\hline
\end{tabular}


Tahap terakhir adalah melakukan interpretasi hasil dari suatu penelitian setelah diadakan uji asumsi klasik dan uji keterandalan baik dengan uji $\mathrm{F}$ dan uji $\mathrm{t}$ serta determinasi.Interpretasi, penafsiran atau penjelasan atas suatu model yang dihasilkan dengan menggunakan koefisien regresi yang meliputi 2 hal yaitu tanda dan besaran.Tanda menunjukkan arah hubungan dan bisa bernilai positif dan negative. Jika angkanya positif menunjukkan pengaruh yang searah antara variable bebas terhadap variable terikat dan jika negative menunjukkan arah yang berlawanan.

Pengertian tanda tersebut adalah positif (searah) jika variable bebas mengalami kenaikan ( peningkatan, bertambah) maka variable terikat juga mengalami hal yang sama. Dalam penelitian ini item $x$ ke 2,3\&4 mengalami hubungan searah (positif). Contoh jika nilai koefisien regresi Motif Fauna, Motif Seni Budaya, Motif Wisata bernilai positif maka kenaikan ketiga variable tersebut menyebabkan kenaikan pada Omzet penjulan di Rumah Joglo Suminar Batik Sekoto Kediri. Motif fauna mempunyai nilai koefisien sebesar $=0,236$, Motif Seni Budaya mempunyai nilai koefisien sebesar $=0,021$ dan motif Wisata mempunyai nilai koefisien sebesar $=0,267$.

Sedangkan arti tanda negative adalah menunjukkan arah yang berlawanan jika variable bebas mengalami kenaikan maka variable terikat mengalami penurunan, hal ini juga berlaku sebaliknya.Jika variable bebas mengalami penurunan maka variable terikat mengalami kenaikan.Dalam penelitian ini yang mengandung nilai negative adalah koefisien regresinya motif Flora dan motif Sosial. Motif flora mempunyai koefisien regresi sebesar $=-0,011$, sedangkan nilai koefisien Motif social mempunyai koefisien regresi sebesar $=-0,212$.

Perlu dipahami bahwa dalam penelitian ini karena menggunakan data primer atau angket maka tidak dapat diinterpretasikan dengan menggunakan besaran, karena alat ukur variabelnya berupa skala likert dan tidak memiliki satuan hanya menunjukkan gradasi dari nilai kecil ke besar dari tidak suka menjadi suka, dari tidak setuju menjadi setuju , berbeda untuk variable yang mempunyai satuan misalnya, $\mathrm{kg}$, ton, unit, Rp dll. Maka bisa dijelaskan dengan menggunakan besaran.

\section{KESIMPULAN}

Metode penelitian yang digunakan dalam peneltian ini uji multikolinearitas, Uji Autokorelasi, Uji Normalitas, Uji F ,Uji t dan Uji koefisien determinasi. Berdasarkan uji multikolinearitas dari 5 variabel yang di teliti, 2 mengandung multikolinearitas dan 3 variabel terbebas dari multikolinearitas. 2 Variabel tersebut adalah variable motif flora dan motif fauna.Tiga variable yang terbebas dari multikolinearitas adalah motif senibudaya, motif wisata, motif social.Hasil dari Uji Autokorelasi diperoleh nilai Durbin-Watson sebesar 0,450 berada pada posisi terjadi auto korelasi positif. Berdasarkan Uji Kelayakan Model, atau uji $\mathrm{F}$ model regresi yang diestimasikan layak. Hasil Uji koefisien determinasi, menghasilkan $\mathrm{R}$ Square yang sangat siknifikan sebesar 0,887. Hasil Interpretasi Model, diperoleh persamaan regresi y $=14,429+(-$ $0.011) \times 1+0,236 \times 2+0,021 \times 3+0,267 \times 4+(-0,212)$

\section{DAFTAR PUSTAKA}

(1) Sugiyono, (2011), Statistika Untuk Penelitian, Alfabeta: Bandung 
(2) Sedarmayanti, ( 2002 ), Metode Penelitian, Mandar Maju : Bandung

(3) Hasan, Iqbal, ( 2004), Analisis Data Penelitian Dengan Statistik, Bumi Aksara : Jakarta

(4) http://ekonomi.kompasiana.com/wirausaha/2013/11/06/cara-jitumeningkatkan-omzet-605655.html

(5) https://jawatimuran.net.2016/10/13>batik

(6) https://id.m.wikipedia.org>wiki>Sejarah

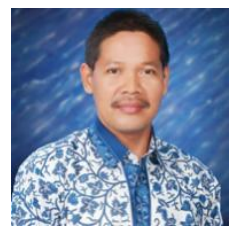

Ustadus Sholihin (Kediri, 7 Oktober 1972) Pendidikan S1 Program Studi Manajemen UNISKA Kediri dan S2 Program Studi Magister Manajement (MM) Uniska Kediri. Aktif dalam beberapa kegiatan Ilmiah , Seminar dan Talkshow dll. Sebagai Pengurus ISEI komisariat Kediri.Pernah Menjabat sebagai kaprodi Manajemen 2004 - 2009 dan Tahun 2013 - 2016.Dekan Fakultas Ekonomi Uniska Hingga sekarang. 